\title{
PROPRIEDADES ENERGÉTICAS DA MADEIRA DE ESPÉCIES NATIVAS DO BRASIL
}

\author{
Leonardo Antônio Moraes Zaque ${ }^{1}$ \\ Mayra Daniela Ferreira² \\ Maria Tereza Campos Carvalho ${ }^{3}$ \\ André Luís de Souza Ferreira ${ }^{4}$ \\ Aylson Costa Oliveira ${ }^{5}$ \\ Bárbara Luísa Corradi Pereira ${ }^{6}$
}

\section{INTRODUÇÃO}

O uso da biomassa florestal para a geração de energia teve grande contribuição histórica para o desenvolvimento da humanidade. A madeira foi a primeira fonte energética do homem, utilizada para geração de calor e cocção de alimentos (GUARDABASSI, 2006). Com o passar do tempo, passou a ser utilizada como combustível sólido, líquido e gasoso em processos para a geração de energia térmica, mecânica e elétrica.

Conforme Trugilho (2012) sendo a biomassa florestal uma fonte de energia primária, renovável e disponível, promove a fixação do carbono atmosférico e contribui para a redução do efeito estufa. Segundo Brand (2007), a biomassa florestal participa da matriz energética mundial, com maior ou menor intensidade em cada país. Seu uso é afetado por variáveis como o nível de desenvolvimento do país, preço, disponibilidade e competição com outras fontes energéticas como petróleo, gás natural, hidroeletricidade, energia nuclear e outras.

1 Mestrando PPG em Ciências Florestais e Ambientais. UFMT. leonardo zaque@hotmail.com

2 Mestranda PPG em Ciências Florestais e Ambientais. UFMT. mayradaniela90@gmail.com

$3 \mathrm{MsC}$ em Ciências Florestais e Ambientais. Secretaria de Estado de Justiça e Direitos Humanos - SEJUDH-MT, mariacarvalho@sejudh.mt.gov.br

4 Mestrando PPG em Ciências Florestais e Ambientais, aluissouza@hotmail.com

5 Prof. Dr. PPG em Ciências Florestais e Ambientais. FENF. UFMT, aylsoncosta@gmail.com

6 Prof. Dra.PPG em Ciências Florestais e Ambientais. FENF. UFMT, babicorradi@gmail.com 
Do ponto de vista energético, biomassa é todo recurso renovável oriundo de matéria orgânica que pode ser utilizado para produção de energia (ORELLANA, 2015). Entretanto, no Brasil, a principal fonte de biomassa utilizada é, em grande parte, a madeira e, quando se avalia a produção de energia, pode-se dizer que seu uso é direcionado à produção de carvão vegetal (carbonização) e consumo direto da lenha (queima) (VALE et al., 2002).

Além disso, o Brasil tem investido no uso da biomassa proveniente de resíduos florestais, industriais e agrícolas, e ainda nos plantios energéticos.

É possível utilizar a biomassa florestal oriunda de florestas nativas, que são exploradas para atender o mercado por meio do manejo florestal, explorando de forma planejada e controlada $\mathrm{s}$ florestas nativas. Entretanto, a utilização de madeira nativa para produção de energia deve partir do princípio de sustentabilidade, ou seja, prevendo uma utilização que permite a recomposição da floresta de uma determinada área, viabilizando-a econômica, socialmente e ambientalmente (ZENID, 2009). Segundo Silva et al. (2014), sob regime de Plano de Manejo Florestal Sustentável, é possível viabilizar a exploração florestal otimizando o aproveitamento da madeira, inclusive com a utilização dos resíduos, contemplando a sustentabilidade dos recursos naturais.

Embora os estudos sobre as espécies florestais nativas sejam de interesse há muitos anos, poucos estudos são dedicados às propriedades físicas, químicas e mecânicas da madeira (SILVA et al., 2014). Contudo, avaliar a qualidade da madeira é de extrema importância quando se objetiva a conversão energética, seja na queima direta ou na produção de carvão vegetal (Santos et al., 2013), para que a produção de energia seja otimizada.

Para a utilização da madeira como matéria-prima para produção de energia e obter um melhor rendimento energético deve-se levar em consideração várias características da sua composição química, além da densidade da madeira. Os teores de celulose, hemiceluloses, lignina, extrativos e substâncias minerais variam com a espécie, e são de grande importância para a escolha adequada da madeira a ser utilizada como fonte energética (TRUGILHO, 2012). De acordo com Oliveira (2010), a qualidade da madeira também é um fator de extrema importância quando o objetivo é a produção 
de carvão vegetal com alto rendimento energético, baixo custo e elevada qualidade. Dessa forma, ao realizar o recorte literário, como estado da arte, sobre propriedades energéticas de espécies madeireiras nativas do Brasil, este trabalho constitui a importância científica em questão.

\section{Densidade da madeira}

A densidade básica madeira é uma característica considerada, por Trugilho (2012) e Almeida et al. (2015), como índice para a avaliação de qualidade para os diferentes produtos, pois está associada com outras propriedades intrínsecas da madeira. Entretanto, não se deve usar a densidade básica de forma isolada na classificação ou seleção de indivíduos para determinado tipo de uso da madeira. Especificamente quando se tem como objetivo o uso da madeira para fins energéticos, a densidade básica deve ser avaliada conjuntamente com a produtividade volumétrica de madeira para a determinação da produção de massa seca da madeira (ROCHA, 2011).

Conforme Vidaurre et al. (2012), quanto maior a densidade da madeira, maior a quantidade de energia contida por unidade de volume, o que estimula o interesse por espécies mais densas para queima, contribuindo para a otimização de transporte e de processo. Na Tabela 1 são apresentados valores de densidade básica média da madeira e a densidade aparente média do carvão de nove espécies de diversas regiões do Brasil, encontrados na literatura.

\begin{tabular}{|c|c|c|c|c|c|c|}
\hline \multirow[b]{2}{*}{ Espécie } & \multirow[b]{2}{*}{$\begin{array}{c}\text { Ocorrência } \\
\text { no Brasil }\end{array}$} & \multicolumn{2}{|c|}{$\begin{array}{c}\text { Densidade básica da } \\
\text { madeira }\end{array}$} & \multicolumn{2}{|c|}{$\begin{array}{l}\text { Densidade Aparente } \\
\text { do carvão vegetal }\end{array}$} & \multirow[b]{2}{*}{ Autores } \\
\hline & & $\begin{array}{c}\text { Valor } \\
\text { médio } \\
\left(\mathrm{kg} / \mathrm{m}^{3}\right)\end{array}$ & $\begin{array}{c}\text { Norma ou } \\
\text { Metodologia }\end{array}$ & $\begin{array}{c}\text { Valor } \\
\text { médio } \\
\left(\mathrm{kg} / \mathrm{m}^{3}\right)\end{array}$ & $\begin{array}{c}\text { Norma ou } \\
\text { Metodologia }\end{array}$ & \\
\hline $\begin{array}{c}\text { Amburana } \\
\text { cearenses } \\
\text { (Allemao) A. C. } \\
\text { Smith }\end{array}$ & $\begin{array}{c}\text { Nordeste, } \\
\text { Centro-Oeste } \\
\text { e Sudeste }\end{array}$ & 631,81 & Vital (1984) & 301 & $\begin{array}{c}\text { ASTM- } \\
\text {-D-167-73, } \\
\text { adaptada por } \\
\text { Oliveira et al., } \\
\text { (1982) }\end{array}$ & $\begin{array}{l}\text { Almeida et al. } \\
\qquad(2015)\end{array}$ \\
\hline $\begin{array}{c}\text { Combretum } \\
\text { leprosum Mart. }\end{array}$ & $\begin{array}{c}\text { Nordeste e } \\
\text { Pantanal }\end{array}$ & 680 & Vital (1984) & 400 & Vital (1984) & $\begin{array}{l}\text { Carneiro et al. } \\
\qquad(2013)\end{array}$ \\
\hline $\begin{array}{c}\text { Caryocar } \\
\text { Brasiliense } \\
\text { Camb. }\end{array}$ & $\begin{array}{c}\text { Centro-Oes- } \\
\text { te, Sudeste, } \\
\text { Norte e } \\
\text { Nordeste }\end{array}$ & 610 & $\begin{array}{c}\text { Foelkel et al. } \\
\text { (1971) e Vital } \\
\text { (1984). }\end{array}$ & - & - & Vale et al. (2002) \\
\hline
\end{tabular}

Continua... 


\begin{tabular}{|c|c|c|c|c|c|c|}
\hline $\begin{array}{l}\text { Handroanthus } \\
\text { impertiginosus } \\
\text { (Mart. ex DC.) }\end{array}$ & \begin{tabular}{|c|} 
Sudeste, \\
Nordeste e \\
Centro-Oeste
\end{tabular} & 997,75 & Vital (1984) & - & - & $\begin{array}{l}\text { Medeiros Neto } \\
\text { et al. (2012) }\end{array}$ \\
\hline $\begin{array}{c}\text { Miconia } \\
\text { cinnamomifolia } \\
\text { (De Candolle) } \\
\text { Naudin } \\
\end{array}$ & $\begin{array}{c}\text { Espirito } \\
\text { Santo e Santa } \\
\text { Catarina }\end{array}$ & 552 & $\begin{array}{c}\text { NBR11491 } \\
\text { (ABNT, 2003) }\end{array}$ & 290 & - & $\begin{array}{c}\text { Brand et al. } \\
\text { (2013) }\end{array}$ \\
\hline $\begin{array}{c}\text { Mimosa } \\
\text { scabrella Benth }\end{array}$ & Sul & $405^{a}$ & $\begin{array}{c}\text { NBR } 11941 \\
\text { (ABNT, 2003) }\end{array}$ & $259^{b}$ & $\begin{array}{c}\text { ASTM- } \\
-\mathrm{D}-167-73\end{array}$ & $\begin{array}{c}\text { Eloy }^{\text {a }} \text { et al.(2015); } \\
\text { Klitzke }^{\mathrm{b}}(1998)\end{array}$ \\
\hline $\begin{array}{c}\text { Mimosa } \\
\text { tenuiflora } \\
\text { (Willd.) Poiret }\end{array}$ & Nordeste & 900 & Vital (1984) & 640 & Vital (1984) & $\begin{array}{l}\text { Carneiro, et al. } \\
\qquad(2013)\end{array}$ \\
\hline $\begin{array}{c}\text { Piptadenia } \\
\text { stipulacea } \\
\text { (Benth.) Ducke }\end{array}$ & Nordeste & 1001,93 & Vital (1984) & 468 & $\begin{array}{c}\text { ASTM- } \\
\text {-D-167-73, } \\
\text { adaptada por } \\
\text { Oliveira et al., } \\
\text { (1982) }\end{array}$ & $\begin{array}{l}\text { Almeida et al. } \\
\qquad(2015)\end{array}$ \\
\hline $\begin{array}{l}\text { Qualea } \\
\text { parviflora } \\
\text { Mart. }\end{array}$ & \begin{tabular}{|c|} 
Centro-Oes- \\
te, Sudeste, \\
Norte e \\
Nordeste \\
\end{tabular} & $690^{c}$ & $\begin{array}{c}\text { Foelkel et al. } \\
\text { (1971) e Vital } \\
(1984)\end{array}$ & $410,7^{d}$ & Vital (1984) & $\begin{array}{l}\text { Vale et al. } \\
\text { (2002); Protásio } \\
\text { et al. (2011) }\end{array}$ \\
\hline $\begin{array}{c}\text { Schizolobium } \\
\text { amazonicum } \\
\text { Huber ex Ducke }\end{array}$ & $\begin{array}{c}\text { Norte e Cen- } \\
\text { tro-Oeste }\end{array}$ & 281,75 & $\begin{array}{l}\text { NBR 7190/97 } \\
\text { (ABNT, 1997) }\end{array}$ & 170 & $\begin{array}{l}\text { NBR 9165/95 } \\
\text { (ABNT, 1997) }\end{array}$ & $\begin{array}{l}\text { Vidaurre et al. } \\
\qquad(2012)\end{array}$ \\
\hline
\end{tabular}

Tabela 1. Valores de densidade básica média da madeira e a densidade aparente média do carvão de espécies nativas brasileiras.

As espécies Piptadenia stipulacea e a Mimosa tenuiflora foram as que apresentaram maiores densidades básicas da madeira e consequentemente maiores densidades aparentes do carvão. Quanto aos menores valores de densidade básica, observou-se nas espécies Schizolobium amazonicum e Mimosa scabrella que estas obtiveram inferior densidade aparente para carvão vegetal. Segundo Vale et al. (2010), quanto maior for à densidade da madeira, mais denso será o carvão vegetal e maior será a quantidade de energia por unidade de volume desse biocombustível. Portanto, o uso de madeiras com alta densidade para produção de carvão vegetal irá fornecer maior rendimento em massa de carvão, já que para um mesmo volume do forno, madeiras mais densas representam maior massa enfornada, quando equiparadas com madeiras menos densas (SANTOS, et al., 2012). Além disso, quanto maior a densidade do carvão maior será a sua resistência mecânica durante o transporte e no dentro dos altos fornos (COSTA et al., 2014).

De acordo com Vale et al., (2002), o uso de madeiras com baixa densidade para a produção direta de energia na forma de calor, implica em uma queima rápida e em menor produção 
de energia por unidade de volume, ao contrário de madeiras mais densas. Todavia, densidades muito elevadas da madeira provocam dificuldade de iniciar a queima do material. Logo, em concordância a Tabela 1, observa-se que as espécies Schizolobium amazonicum e Mimosa scabrella apresentam baixas densidades, variável esta que consequentemente acarretaria em uma queima rápida e reduzida produção energética. Já as espécies Piptadenia stipulacea e a Mimosa tenuiflora apresentam maiores densidades, logo, estas revelariam certa dificuldade para iniciar a queima do material.

Conforme Vale et al., (2002), para a queima direta na cocção de alimentos, a densidade básica deve variar entre $650 \mathrm{~kg} / \mathrm{m}^{3}$ a $800 \mathrm{~kg} / \mathrm{m}^{3}$ para facilitar o início da queima. Portanto objetivando queima direta na cocção de alimentos, dentre as espécies elencadas na Tabela 1, recomenda-se as espécies Qualea parviflora e Combretum leprosum.

\section{Poder Calorífico e Densidade Energética}

O poder calorífico é uma das principais variáveis usadas para selecionar espécies para fins energéticos, já que está relacionado com a quantidade de energia liberada durante sua queima (CARNEIRO et al., 2013).

Jara (1989) define o poder calorífico como a quantidade de energia na forma de calor liberada pela combustão de uma unidade de massa da madeira, expresso em calorias por grama (cal/g) ou quilocaloria/quilograma (kcal/kg). Segundo Carvalho Júnior (2010), quanto maior for este parâmetro, maior será a energia contida no combustível. A madeira possui poder calorífico variável, dependendo da espécie. Madeiras de coníferas possuem poder calorífico superior médio de $5.200 \mathrm{kcal} / \mathrm{kg}$, enquanto que as madeiras de folhosas, conforme as espécies aqui observadas, possuem poder calorífico superior médio de $4.500 \mathrm{kcal} / \mathrm{kg}$ (TRUGILHO, 2012).

A densidade energética indica o potencial energético da madeira, em unidade de energia por volume. A densidade energética, em $\mathrm{kcal} / \mathrm{m}^{3}$ e $\mathrm{GJ} / \mathrm{m}^{3}$, foi calculada a partir da multiplicação dos valores médios de poder calorífico superior e a densidade básica da madeira. A capacidade requerida para transporte e armazenamen- 
to de madeira é reduzida com o aumento densidade de energia, razão pela elevada densidade energética é de grande importância, sobretudo por razões econômicas.

Na Tabela 2 são apresentados valores médios de poder calorífico da madeira e densidade energética de nove espécies de diversas regiões do Brasil, encontrados na literatura.

\begin{tabular}{|c|c|c|c|c|}
\hline Espécie & $\begin{array}{c}\text { Poder calorífico } \\
\text { superior da ma- } \\
\text { deira (kcal/kg) }\end{array}$ & Normas & Autores & $\begin{array}{c}\text { Densidade } \\
\text { Energética } \\
\left(\mathrm{GJ} / \mathrm{m}^{3}\right)\end{array}$ \\
\hline $\begin{array}{c}\text { Amburana } \\
\text { cearensis }\end{array}$ & 4369 & $\begin{array}{l}\text { NBR 8633/83 } \\
\text { (ABNT, 1983) }\end{array}$ & Almeida et al., (2015) & 11,54 \\
\hline $\begin{array}{c}\text { Combretum } \\
\text { leprosum }\end{array}$ & 4602 & $\begin{array}{l}\text { NBR 8633/84 } \\
\text { (ABNT, 1983) }\end{array}$ & Carneiro, et al., (2013) & 13,09 \\
\hline $\begin{array}{c}\text { Caryocar } \\
\text { brasiliense }\end{array}$ & 4839,10 & $\begin{array}{l}\text { NBR 8633/84 } \\
\text { (ABNT, 1983) }\end{array}$ & Vale et al., (2002) & 12,35 \\
\hline $\begin{array}{l}\text { Handroanthus } \\
\text { impertiginosus }\end{array}$ & 4806,30 & $\begin{array}{l}\text { NBR 8633/84 } \\
\text { (ABNT, 1983) } \\
\end{array}$ & \begin{tabular}{|c|} 
Medeiros Neto et al., \\
$(2012)$
\end{tabular} & 20,07 \\
\hline $\begin{array}{c}\text { Miconia } \\
\text { cinnamomifolia }\end{array}$ & 4178 & DIN 51900/2000 & Brand et al., (2013) & 9,64 \\
\hline $\begin{array}{c}\text { Mimosa } \\
\text { scabrella Benth }\end{array}$ & 4357 & $\begin{array}{l}\text { NBR 8633/84 } \\
\text { (ABNT, 1984) }\end{array}$ & Eloy et al.,(2015) & 7,38 \\
\hline $\begin{array}{l}\text { Mimosa } \\
\text { tenuiflora }\end{array}$ & 4823 & $\begin{array}{l}\text { NBR 8633/84 } \\
\text { (ABNT, 1983) }\end{array}$ & Carneiro, et al., (2013) & 18,16 \\
\hline $\begin{array}{l}\text { Piptadenia } \\
\text { stipulacea }\end{array}$ & 4584 & $\begin{array}{l}\text { NBR 8633/83 } \\
\text { (ABNT, 1983) } \\
\end{array}$ & Almeida et al., (2015) & 19,21 \\
\hline $\begin{array}{c}\text { Qualea } \\
\text { parviflora }\end{array}$ & 4710,50 & $\begin{array}{l}\text { NBR 8633/84 } \\
\text { (ABNT, 1983) } \\
\end{array}$ & Vale et al., (2002) & 13,59 \\
\hline $\begin{array}{l}\text { Schizolobium } \\
\text { amazonicum }\end{array}$ & 4519 & $\begin{array}{l}\text { NBR 8633/83 } \\
\text { (ABNT, 1983) }\end{array}$ & Vidaurre et al., (2012) & 5,32 \\
\hline
\end{tabular}

Tabela 2. Valores médios de poder calorífico de madeira de espécies nativas brasileiras.

Segundo Vidaurre et al. (2012) a densidade não possui relação direta com o poder calorífico da madeira e os valores das Tabelas 1 e 2 corroboram essa afirmação. Caryocar brasiliense apresentou maior poder calorífico e a densidade básica foi inferior a algumas espécies apresentadas na Tabela 1, e a espécie Schizolobium amazonicum, que apresentou a menor densidade básica, obteve poder calorífico maior quando comparado a algumas espécies já citadas.

Silva et al. (2014), estudando quatro espécies tropicais (Scleronema micranthum, Scleronema sp, Ocotea sp e Caryocar villosum), 
encontraram efeito direto positivo entre a densidade energética e densidade básica, pois espécies mais densas corroboram para maior densidade energética, que é a expressão de energia por unidade de volume. Piptadenia stipulacea e Mimosa tenuiflora atingiram maiores valores de densidade energética, pois obtiveram maiores densidades básicas e também poder calorífico elevado. Já as espécies Mimosa scabrella Benth e Schizolobium amazonicum apresentaram menores valores para densidade energética, pelo fato de conterem as menores densidades básicas e valores inferiores às demais espécies para o poder calorífico.

\section{Composição Química}

Os constituintes químicos presentes na madeira são holoceluloses (celulose e hemiceluloses) e lignina, além de uma menor quantidade de extrativos e materiais inorgânicos (cinzas) (SANTOS, 2008). O rendimento energético de um processo de combustão da madeira depende de sua constituição química que varia com a espécie e é fundamental para escolha correta da madeira a ser usada (QUIRINO et al., 2005).

A porcentagem de holoceluloses corresponde a uma fração mais significativa da massa da madeira, sendo representada pelos componentes estruturais que são os carboidratos. O comportamento da celulose e das hemiceluloses, diante da degradação térmica, apresenta um perfil bastante instável e pouco resistente, principalmente as hemiceluloses, por serem constituintes químicos que apresentam natureza amorfa e ramificada, contribuindo para maior degradação da madeira (SANTOS, 2010).

Na Tabela 3 são apresentados os valores médios percentuais referentes à holoceluloses e lignina de nove espécies nativas do Brasil, encontrados na literatura. 


\begin{tabular}{|c|c|c|c|c|}
\hline Espécie & $\begin{array}{l}\text { Holocelu- } \\
\text { lose (\%) }\end{array}$ & $\begin{array}{l}\text { Lignina } \\
(\%)\end{array}$ & Normas & Autores \\
\hline $\begin{array}{l}\text { Amburana } \\
\text { cearenses }\end{array}$ & 49,27 & 21,14 & $\begin{array}{c}\text { Método de Klason, modificado } \\
\text { por Gomide e Demurier (1986), } \\
\text { mais a soma da lignina solúvel } \\
\text { conforme Goldschimid (1971) }\end{array}$ & $\begin{array}{l}\text { Almeida et al., } \\
\text { (2015) }\end{array}$ \\
\hline $\begin{array}{l}\text { Combretum } \\
\text { leprosum }\end{array}$ & - & 29,77 & T 222 om-98 & França (2015) \\
\hline $\begin{array}{l}\text { Handroanthus } \\
\text { impertiginosus }\end{array}$ & 63,85 & 28,40 & $\begin{array}{c}\text { Método de Klason, modificado } \\
\text { por Gomide e Demurier (1986), } \\
\text { mais a soma da lignina solúvel } \\
\text { conforme Goldschimid (1971), } \\
\text { e holocelulose }(\%)=100-\text { (teor } \\
\text { de extrativos + teor de lignina + } \\
\text { cinzas na madeira) }\end{array}$ & $\begin{array}{c}\text { Medeiros Neto et } \\
\text { al., (2012) }\end{array}$ \\
\hline $\begin{array}{l}\text { Mimosa } \\
\text { tenuiflora }\end{array}$ & 60,28 & 29,14 & \begin{tabular}{|c} 
Para lignina Gomide \& Demuner \\
$(1986)$, e holocelulose $(\%)=100$ \\
- (teor de extrativos + teor de \\
lignina + cinzas na madeira)
\end{tabular} & Paes et al., (2013) \\
\hline $\begin{array}{l}\text { Piptadenia } \\
\text { stipulacea }\end{array}$ & 59,68 & 25,84 & $\begin{array}{c}\text { Método de Klason, modificado } \\
\text { por Gomide e Demurier (1986), } \\
\text { mais a soma da lignina solúvel } \\
\text { conforme Goldschimid (1971) }\end{array}$ & $\begin{array}{c}\text { Almeida et al., } \\
\text { (2015) }\end{array}$ \\
\hline $\begin{array}{l}\text { Schizolobium } \\
\text { amazonicum }\end{array}$ & - & 29,5 & TAPPI 222 om-98 & $\begin{array}{l}\text { Vidaurre et al., } \\
\text { (2012) }\end{array}$ \\
\hline
\end{tabular}

Tabela 3. Valores percentuais referentes à holocelulose e lignina de madeira de espécies nativas brasileiras.

Conforme Paula (1993), para a madeira, a celulose e lignina são as substâncias básicas usadas para geração de energia, portanto, do ponto de vista ecológico e econômico, as madeiras ricas nessas substâncias são as mais viáveis e promissoras para a produção de energia. Contudo, quando se objetiva a produção de carvão vegetal, o rendimento em carvão vegetal está intimamente relacionado à composição química da madeira, no que se diz respeito a elevados teores de lignina. Vale salientar que a temperatura de 450 ㄷ C é a máxima recomendada para a produção de carvão vegetal, sendo que nesta temperatura é possível atrelar maiores rendimentos à qualidade do carvão vegetal. A partir desta temperatura, a degradação da lignina começa a ser mais intensa, o que prejudica o rendimento e as propriedades do carvão vegetal.

A condição de queima da madeira para produção de energia é considerada como ideal quando se encontra absolutamente seca, mas também é influenciada pela constituição química da mesma 
- lignina e extrativos, que elevam seu potencial (QUIRINO et al., 2005). Os valores da Tabela 2 de poder calorifico relacionando com o teor de lignina da Tabela 3 estão de acordo com a afirmação desses autores, uma vez que as espécies Handroanthus impertiginosus, Mimosa tenuiflora, Combretum leprosum e Schizolobium amazonicum apresentaram maior poder calorifico e de lignina.

\section{Análise Imediata}

Os minerais presentes na madeira são essenciais do ponto de vista energético, pois quando queimados em fornalhas e caldeiras podem formar incrustações nos equipamentos e nas tubulações. Quando se produz carvão vegetal para ser utilizado na siderurgia, deve-se possuir baixo teor de minerais, pois esses provocam problemas na qualidade do aço produzido (BARCELLOS et al., 2005).

As propriedades físicas e químicas das cinzas de madeira determinam seus usos benéficos, que dependem das espécies da madeira e dos métodos de combustão que incluem temperatura de combustão, eficiência da caldeira e combustíveis suplementares usados (SIDDIQUE, 2009). As cinzas são substâncias compostas de material inorgânico e possuem relação inversa com o poder calorífico (CHAVES et al., 2013).

O carbono fixo apresenta relação direta com o poder calorífico (CHAVES et al., 2013). O poder calorífico superior apresenta valores maiores quando associado aos maiores valores de carbono fixo, porém em relação ao teor de materiais voláteis, o poder calorífico superior é menor quando os materiais voláteis possuem maiores valores (PROTÁSIO et al., 2012).

Existe alta correlação entre o poder calorífico superior e o teor de carbono fixo. Em relação à influência do teor de materiais voláteis no poder calorífico, há uma relação negativa. Os teores de carbono fixo e materiais voláteis são inversamente proporcionais, uma vez que a primeira variável é obtida por diferença (PROTÁSIO et al., 2011).

Na Tabela 4 são apresentados valores médios de Materiais Voláteis, Carbono Fixo, Cinzas de nove espécies nativas do Brasil, encontrados na literatura. 


\begin{tabular}{c|c|c|c|c|c}
\hline Espécie & $\begin{array}{c}\text { Materiais } \\
\text { Voláteis }\end{array}$ & $\begin{array}{c}\text { Carbono } \\
\text { Fixo }\end{array}$ & Cinzas & $\begin{array}{c}\text { Norma ou } \\
\text { Metodologia }\end{array}$ & Autores \\
\hline Caryocar brasiliense & 80,13 & 19,50 & 0,37 & $\begin{array}{c}\text { ASTM } \\
\text { D-1762/64. }\end{array}$ & $\begin{array}{c}\text { Vale et al., } \\
\text { (2002) }\end{array}$ \\
\hline $\begin{array}{c}\text { Combretum } \\
\text { leprosum }\end{array}$ & 83,15 & 15,72 & 1,13 & $\begin{array}{c}\text { ABNT NBR } \\
8112\end{array}$ & $\begin{array}{c}\text { Santos, et al., } \\
\text { (2011) }\end{array}$ \\
\hline $\begin{array}{c}\text { Miconia } \\
\text { cinnamomifolia }\end{array}$ & 80,17 & 19,99 & 0,84 & $\begin{array}{c}\text { ASTM 1762 } \\
\text { (ASTM, 2007) }\end{array}$ & $\begin{array}{c}\text { Brand et al., } \\
\text { (2013) }\end{array}$ \\
\hline $\begin{array}{c}\text { Mimosa scabrella } \\
\text { Benth }\end{array}$ & 81,87 & 16,535 & 1,695 & $\begin{array}{c}\text { ABNT NBR } \\
8112\end{array}$ & $\begin{array}{c}\text { Eloy et } \\
\text { al.,(2015) }\end{array}$ \\
\hline Mimosa tenuiflora & 80,98 & 18,55 & 0,47 & $\begin{array}{c}\text { ABNT NBR } \\
8112\end{array}$ & $\begin{array}{c}\text { Santos, et al., } \\
\text { (2011) }\end{array}$ \\
\hline Qualea parviflora & 77,07 & 22,12 & 0,81 & $\begin{array}{c}\text { ASTM } \\
\text { D-1762/64. }\end{array}$ & $\begin{array}{c}\text { Vale et al., } \\
\text { (2002) }\end{array}$ \\
\hline
\end{tabular}

Tabela 4. Valores médios sobre Materiais Voláteis, Carbono Fixo, Cinzas de madeira de espécies nativas brasileiras.

Conforme Santos et al. (2013) as cinzas afetam negativamente o poder calorífico. Afirmação que se comprova uma vez que os valores de poder calorífico são maiores e teores de cinzas menores nas Tabelas 2 e 4 para as espécies Mimosa tenuiflora e Caryocar brasiliense.

Conforme Oliveira (2003), maiores teores de carbono fixo e menores teores de substancias voláteis e cinzas estão associados à madeira com altos teores de lignina, para determinadas condições de carbonização. As espécies da Tabela 4 traduzem a hipótese da autora, pois apresentaram maiores teores de carbono fixo e obtiveram menores teores de materiais voláteis e cinzas, a exemplo, Qualea parviflora, Miconia cinnamomifolia e Caryocar brasiliense. Quanto às espécies com maior teor de liginina, conforme (Tabela 3), de modo geral, foram as que também apresentaram maior teor de carbono fixo.

Conforme Chaves et al., (2013), um maior teor de carbono fixo implica em um maior tempo de residência dentro do aparelho de queima, sendo uma vantagem para o cozimento de alimentos, uma vez que aparelhos de queima no meio rural (fogões) tem eficiência baixa no uso de calor produzido (VALE et al., 2002). As espécies da Tabela 4, que poderiam ser utilizadas na zona rural seriam Qualea parviflora, Caryocar brasiliense, Miconia cinnamomifolia e Mimosa tenuiflora, pois apresentaram maiores teores de carbono fixo. 


\section{CONSIDERAÇÕES FINAIS}

As propriedades energéticas como densidade, poder calorífico, composição química e análise imediata são importantes como subsídio para auxiliar na seleção das espécies de acordo com o uso final. Todavia, um equívoco seria avaliá-las isoladamente.

Para a densidade, conforme as espécies estudadas, nota-se que quanto maior for a densidade básica da madeira maior será a densidade aparente do carvão vegetal. Já para a análise imediata é necessário controlar os teores de carbono fixo e materiais voláteis, uma vez que estes influenciam na velocidade de queima do material. Em relação às cinzas, essas são indesejáveis, pois reduzem o poder calorífico.

As espécies nativas com melhores características com potencial energético para queima rápida são Schizolobium amazonicum e Mimosa scabrella, já para uma queima lenta e para a produção de carvão vegetal as melhores espécies são Piptadenia stipulacea e a Mimosa tenuiflora e para a cocção de alimentos as mais recomendadas são Qualea parviflora e Combretum leprosum.

\section{REFERÊNCIAS}

ASSOCIAÇÃO BRASILEIRA DE NORMAS TÉCNICAS-ABNT NBR 7190-Brasília, 1997. ASSOCIAÇÃO BRASILEIRA DE NORMAS TÉCNICAS - ABNT NBR 8112:1986 - Carvão vegetal - Análise imediata. Rio de Janeiro,1986.

ASSOCIAÇÃO BRASILEIRA DE NORMAS TÉCNICAS - ABNT NBR 8633. Rio de Janeiro, 1983.

ASSOCIAÇÃO BRASILEIRA DE NORMAS TÉCNICAS - ABNT NBR - 9165 - Brasília, 1997.

ASSOCIAÇÃO BRASILEIRA DE NORMAS TÉCNICAS - ABNT (2003) NBR 11491 Determinação da Densidade Básica. Rio de Janeiro ,2003.

ASTM - AMERICAN SOCIETY FOR TESTING AND MATERIAL Standard Test Method for Chemical Analysis of Wood Charcoal. D 1762 - 84, 2001 (2007).

ALMEIDA, A. M. C..; OLIVEIRA, E.; CALEGARI, L.; MEDEIROS NETO, P. N.; PIMENTA, A. S. Avaliação físico-química e energética da madeira das espécies Piptadenia stipulacea (Benth.) Ducke e Amburana cearenses (Allemao) A. C. Smith de ocorrência no semiárido nordestino brasileiro. Ciência Florestal, Santa Maria, v.25, n.1, p.165-173, 2015. 
BARCELLOS, D. C.; COUTO, L. C.; MULLER, M. D.; COUTO, L. O estado-da-arte da qualidade da madeira de eucalipto para produção de energia: Um enfoque nos tratamentos silviculturais. Renabio-Biomassa e Energia, v. 2. N.2, p. 141-158, 2005.

BRAND, M. A.; CUNHA, A. B.; CARVALHO, A. F.; BREHMER, D. R.; KUSTER, L. C. Análise da qualidade da madeira e do carvão vegetal produzido a partir da espécie Miconia cinnamomifolia (De Candolle) Naudin (Jacatirão-açu) na agricultura familiar, em Biguaçu, Santa Catarina. Scientia Forestalis, Piracicaba, v. 41, n. 99, p.401-410, set, 2013.

BRAND, M. A. Qualidade da biomassa florestal para o uso na geração de energia em função da estocagem. Tese (Doutorado) - Universidade Federal do Paraná, Curitiba, 165 p, 2007.

CARNEIRO, A. C. O.; SANTOS, R. C.; CASTRO, R. V. O.; CASTRO, A. F. N. M.; PIMENTA, A. S.; PINTO, E. M. ALVES, I. C. N. Estudo da decomposição térmica da madeira de oito espécies da região do Seridó, Rio Grande do Norte. Revista Árvore, Viçosa-MG, v. 37, n. 6, p. 1153-1163, 2013.

CARVALHO JÚNIOR, R.M. Desenvolvimento e análise energética do processo de obtenção do biodiesel de microalga por metanólise in situ. Dissertação (Mestrado) UFPR, Curitiba - PR, 2010.

CHAVES, A. M. B.; VALE, A. T.; MELIDO, R. C. N.; ZOCH, V. P. Características energéticas da madeira e carvão vegetal de clones de Eucalyptus spp. Enciclopédia Biosfera, Goiânia, v. 9, n. 17, p. 533-542, 2013.

COSTA, T. G.; BIANCHI, M. L.; PROTÁSIO, T. de P.; TRUGILHO, P. F.; PEREIRA, A. J. Qualidade da madeira de cinco espécies de ocorrência no cerrado para produção de carvão vegetal. Cerne, Lavras - MG, v.20, n.1, p. 37-46, jan/mar, 2014.

DIN - DEUTSCHES INSTITUT FÜR NORMUNG e. V. DIN 51900: Determining the gross calorific value of solid and liquid fuels using the bomb calorimeter, and calculation of net calorific value. Berlim, 2000.

ELOY, E.; SILVA, D. A. da.; CARON, B. O.; SOUZA, V. Q. de.; BEHLING, A.; ELLI, E. F.; MONTEIRO, G. C. Caracterização da biomassa da madeira e da casca de Mimosa scabrella Benth cultivada em dois diferentes espaçamentos. Ciência da Madeira, v.6. n.1. p.38-46, 2015.

FOELKEL, C.E.B.; BRASIL, M.A.M.; BARRICHELO, L.E.G. Métodos para determinação da densidade básica de cavacos para coníferas e folhosas. IPEF, n.2/3, p.65-74, 1971.

FRANÇA, F. R. Estrutura anatômica da madeira e do carvão de espécies da caatinga. Dissertação (mestrado) - Universidade Federal do Paraná, Setor de Ciências Agrárias, Programa de Pós-Graduação em Engenharia Florestal, 2015.

GOLDSCHIMID, O. Ultraviolet spectra. In: SARKANEN, K. V.; LUDWWIG, C. H. (Eds) Lignins. New York: Wiley Interscience, p. 241-66, 1971. 
GOMIDE, J. L.; DEMUNER, B. J. Determinação do teor de lignina em material lenhoso: método Klason modificado. O PAPEL, v. 47, n. 8, p. 36-38, 1986.

GUARDABASSI, P. M. Sustentabilidade da Biomassa como Fonte de Energia: Perspectivas para Países em Desenvolvimento. Dissertação de mestrado - Programa Interunidades de Pós-Graduação em Energia. Universidade de São Paulo, 123p., 2006.

JARA, E.R.P. O poder calorífico de algumas madeiras que ocorrem no Brasil. São Paulo: Instituto de Pesquisas Tecnológicas - IPT. (Comunicação Técnica, 1797), 1989.

KLITZKE, R. J. Avaliação da bracatinga (Mimosas scabrella Bentham) em função da idade, do teor de umidade da madeira e da temperatura final de carbonização. Dissertação (mestrado) - Universidade Federal do Paraná, Setor de Ciências Agrárias, Programa de Pós-Graduação em Engenharia Florestal. 123p, 1998.

MEDEIROS NETO, P. N.; OLIVEIRA, E.; CALEGARI, L.; ALMEIDA, A. M. C.; PIMENTA, A. S.; CARNEIRO, A. C. O. Características físico-químicas e energéticas de duas espécies de ocorrência no semiárido brasileiro. Ciência Florestal, Santa Maria, v. 22, n. 3, p579-588, jul-set, 2012.

OLIVEIRA, A. O.; CARNEIRO, A. C. O.; VITAL, B. R.; ALMEIDA, W.; PEREIRA, B. L. C.; CARDOSO, M. T. Parâmetros de qualidade da madeira e do carvão vegetal de Eucalyptus pellita F. Muell. Scientia Forestalis. Piracicaba, SP, v.38, n.87, p. 431-439, set, 2010.

OLIVEIRA, E. Características anatômicas, químicas e térmicas da madeira de três espécies de maior ocorrência no semi-árido nordestino. 122 f. Tese (Doutorado em Ciências Florestais) - Universidade Federal de Viçosa, 2003.

OLIVEIRA, J. B.; GOMES, P. A.; ALMEIDA, M. R. Estudos preliminares de normatização de testes de controle de qualidade do carvão vegetal. In: PENEDO, W. R. CARVÃO VEGETAL. Belo Horizonte, CETEC, p. 7-38. (Série de Publicações Técnicas, 006), 1982.

ORELLANA, B. B. M. A. Quantificação da biomassa e potencial energético de Tachigali vulgaris em áreas plantadas no estado do Amapá. Dissertação de Mestrado, Publicação PPG EFL. DM-248/2015, Departamento de Engenharia Florestal, Universidade de Brasília, DF, 77p, 2015.

PAES, J. B.; LIMA, C. R de.; OLIVEIRA, E. de.; MEDEIROS, P. N. Características físico-química, energética e dimensões das fibras de três espécies florestais do semiárido brasileiro. Floresta e Ambiente; 20(4): 550-555, 2013.

PAULA, J. E. Madeiras da caatinga úteis para produção de energia. Pesquisa Agropecuária Brasileira, v. 28, n.2, p.153-165, fev, 1993.

PROTÁSIO, T. P.; BUFALINO, L.; MENDES, R. F.; RIBEIRO, M. X.; TRUGILHO, P. F.; LEITE, E. R. S. Torrefação e carbonização de briquetes de resíduos do processamento dos grãos de café. Revista Brasileira de Engenharia Agrícola e Ambiental. v. 16, n. 11, p. 1252-1258, 2012. 
PROTÁSIO, T. P.; COUTO, T.; REIS, A. A.; TRUGILHO P.F. Seleção de Clones de Eucalyptus para a produção de carvão vegetal e bioenergia por meio de técnicas univariadas e multivariadas. Scientia Forestalis. Piracicaba, v. 41, n. 97, p. 015028, mar, 2013.

PROTÁSIO, T. P.; SANTANA, J. D. P. de.; GUIMARÃES NETO, R. M.; GUIMARÃES JÚNIOR, J. B.; TRUGILHO, P. F.; RIBEIRO, I. B. Avaliação da qualidade do carvão vegetal de Qualea parviflora. Pesquisa Florestal Brasileira, Colombo - PR, v. 31, n. 68, p. 295-307, out/dez, 2011.

QUIRINO, W. F.; VALE, A. T. do.; ANDRADE, A. P. A. de.; ABREU, V. L. S.; AZEVEDO, A. C. S. Poder calorífico da madeira e de materiais ligno-celulósicos. Revista da Madeira, n.89. abr. p. 100-106, 2005.

ROCHA, M. F. V. Influência do espaçamento e da idade na produtividade e propriedades da madeira de Eucalyptus grandis x Eucalyptus camaldulensis para energia. Dissertação (mestrado) - Universidade Federal de Viçosa. Viçosa, MG. 2011.

SANTOS, L. C.; CARVALHO, A. M. M. L.; PEREIRA, B. L. C.; OLIVEIRA, A. C.; CARNEIRO, A. C. O.; TRUGILHO, P. F. Propriedades da madeira e estimativas de massa, carbono e energia de clones de Eucalyptus plantados em diferentes locais. Revista Árvore, Viçosa-MG, v.36, n.5, p.971-980, 2012.

SANTOS, R. C.; CARNEIRO, A. C. O.; CASTRO, R. V. O.; PIMENTA, A. S.; CASTRO, A. F. N. M.; MARINHO, I. V.; VILLAS BOAS, M. A. Potencial de briquetagem de resíduos florestais da região do Seridó, no Rio Grande do Norte. Pesquisa Florestal Brasileira, Colombo, v. 31, n. 68, p. 285-294, out/dez, 2011.

SANTOS, R. C.; CARNEIRO, A. C. O.; CASTRO, R. V. O.; PIMENTA, A. S.; CASTRO, R. V. O.; MARINHO, I. V.; TRUGILHO, P. F.; ALVES, I. C.; CASTRO, A. F. N. M. Potencial energético da madeira de espécies oriundas de plano de manejo florestal no estado do Rio Grande do Norte. Ciência Florestal, Santa Maria, v. 23, n.2, p.493-504, 2013.

SANTOS, I. D. Influência dos teores de lignina, holocelulose e extrativos na densidade básica, contração da madeira e nos rendimentos e densidade do carvão vegetal de cinco espécies lenhosas do cerrado. Departamento de Ciências Florestais. Universidade de Brasília. Dissertação (mestrado) - Programa de Pós-Graduação em Ciências Florestais, 2008.

SANTOS, R. C. Parâmetros de qualidade da madeira e do carvão vegetal de clones de Eucalipto. Tese (doutorado) - Universidade Federal de Lavras. Lavras - MG, 2010. 159p, 2010.

SIDDIQUE, R. Utilization of waste material sand by-products in producing controlled low-strength materials. Resources, Conservation and Recycling, Volume 54, Issue 1, November, Pages 1-8, 2009.

SILVA, D. A.; ALMEIDA, V. C.; VIANA, L. C.; KLOCK, U.; MUÑIZ, G. I. B. Avaliação das Propriedades Energéticas de Resíduos de Madeiras Tropicais com Uso da Espectroscopia NIR. Floresta e Ambiente, 21(4):561-568, 2014. 
TAPPI TEST METHODS. T 222 om-98. Acid-insoluble lignin in wood and pulp. 1998.

TRUGILHO, P. F. Energia da Biomassa Florestal. 4 Congresso Florestal Paranaense 2012. 2012.

VALE, A. T.; BRASIL, M. A. M.; LEÃO, A. L. Quantificação e caracterização energética da madeira e casca de espécies do cerrado. Ciência Florestal, Santa Maria, v.12, n. 1. p.71-80, 2002.

VALE, A. T.; DIAS, I. S.; SANTANA, M. A. E. Relações entre as propriedades químicas, físicas e energéticas da madeira de cinco espécies do cerrado. Ciência Florestal, Santa Maria, v.20, n.1, p.137-145, 2010.

VIDAURRE, G. B.; CARNEIRO, A. C. O.; VITAL, B. R.; SANTOS, R. C.; VALLE, M. L. A. Propriedades energéticas da madeira e do carvão de paricá (Schizolobium amazonicum). Revista Árvore, Viçosa - MG, v.36, n.2, p.365-371, 2012.

VITAL, B. R. Métodos de determinação da densidade da madeira. Viçosa: SIF. 21 p. (Boletim Técnico, 1), 1984.

ZENID, G. J (2009) Madeira: Uso Sustentável na Construção Civil. 2a edição. Instituto de Pesquisas Tecnológicas - IPT, SVMA, 2009. 